Bài báo khoa học

\title{
Nghiên cứu xây dựng các kịch bản ngập cho thành phố Hồ Chí Minh dưới tác động của Biến đổi khí hậu
}

\section{Nguyễn Văn Hồng ${ }^{*}$, Nguyễn Phương Đông ${ }^{1}$}

${ }^{1}$ Phân Viện Khoa học Khí tượng Thủy văn và Biến đổi khí hậu; nguyenvanhong79@gmail.com; donghai930t110@gmail.com

*Tác giả liên hệ: nguyenvanhong79@gmail.com; Tel.: +84-913613206

Ban Biên tập nhận bài: 05/04/2021; Ngày phản biện xong: 22/6/2021; Ngày đăng bài: 25/9/2021

Tóm tắt: Trong những năm qua do tác động của khí hậu cực đoan nên diễn biến của mưa và triều tại thành phố Hồ Chí Minh (TP.HCM) có nhiều thay đổi. Điều đó đã ảnh hưởng lớn đến tình trạng ngập của thành phố, gây thiệt hại cũng như gây trở ngại rất nhiều cho các hoạt động kinh tế xã hội của người dân thành phố. Vì vậy, nghiên cứu về tác động của biến đổi khí hậu đến ngập tại thành phố là rất cần thiết. Trong bài báo này, nghiên cứu đã ứng dụng mô hình MIKE FLOOD để đánh giá diễn biến ngập tại TP.HCM dưới ảnh hưởng của biến đổi khí hậu (lũ thượng nguồn gia tăng trên các sông, mưa cực đoan xảy ra thường xuyên và nước biển dâng) giai đoạn hiện trạng năm 2016 và các kịch bản được chọn cho tính toán tương lai (kịch bản RCP4.5, kịch bản RCP8.5 cho năm 2030 và 2050). Kết quả nghiên cứu cho thấy, diễn biến ngập gia tăng cả về diện tích và độ sâu ngập trong tương lai, đặc biệt là ở kịch bản RCP4.5 cho năm 2050 với diện tích ngập được mô phỏng khoảng 8757,02 ha (chiếm 1,96\% so với diện tích đất tự nhiên của thành phố) và kịch bản RCP8.5 cho năm 2050 với diện tích ngập khoảng 9039,91 ha (chiếm 4,38\% so với diện tích đất toàn thành phố).

Từ khóa: MIKE FLOOD; Ngập; Nước biển dâng; Mưa cực đoan; Thành phố Hồ Chí Minh.

\section{Mở đầu}

Biến đổi khí hậu là một vấn đề mang tính toàn cầu, đã và đang có những tác động rõ nét đến tài nguyên, môi trường, kinh tế xã hội cũng như đời sống của người dân tại rất nhiều quốc gia trên thế giới [1-2]. Việt Nam được đánh giá là một trong những quốc gia bị ảnh hưởng nặng nề bởi biến đổi khí hậu $(\mathrm{BĐKH})$ : mực nước biển dâng cao $1 \mathrm{~m}$ sẽ làm ngập diện tích cư trú của $11 \%$ dân số và $7 \%$ diện tích đất nông nghiệp [3]. Mặc dù có nhiều tác động của biến đổi khí hậu xảy ra trong tương lai, tuy nhiên ngập lụt lại là một trong những vấn đề lớn ở Việt Nam, trong đó một số bộ phận dân số sẽ dễ bị tổn thương hơn so với các nhóm khác [4-7].

Thành phố Hồ Chí Minh (TP.HCM) là một đô thị lớn bởi quy mô đô thị và vai trò, tầm cỡ về phát triển kinh tế. Tuy nhiên, quá trình đô thị hóa tạo ra những cơ hội để phát triển thì nó cũng làm tăng nguy cơ của người dân đô thị vùng ven biển đối với sự biến đổi của khí hậu. Ở TP.HCM dễ bị ngập đô thị hóa, lượng mưa lớn, dòng chảy từ thượng nguồn và nước biển dâng. Bên cạnh đó, thành phố còn được xếp vào những thành phố trên thế giới chịu ảnh hưởng nặng nề nhất bởi biến đồi khí hậu [6].

Diện tích không gian của thành phố Hồ Chí Minh từng được mở rộng từ $86,2 \mathrm{~km}^{2}$ năm 1990 đển $351,1 \mathrm{~km}^{2}$ năm 2010 , và gần $60 \%$ tổng diện tích TP.HCM nằm dưới cao trình 1,5 
$\mathrm{m}$ so với mực nước biển. Do đó, thành phố đối mặt với các vấn đề ngập thường xuyên trong suốt mùa mưa từ tháng 6 đến tháng 11 và chu kỳ triều cường dâng cao từ tháng 9 đến tháng 12 hàng năm và lưu lượng từ thượng nguồn của sông Sài Gòn-Đồng Nai. Có nhiều nguyên nhân dẫn đến tình trạng ngập ở TP.HCM, trong đó nguyên nhân khách quan là do BĐKH, mực nước biển dâng, gia tăng lượng mưa và mức đỉnh triều, do đô thị hóa tăng dẫn đến dân số gia tăng nhanh vượt ngoài khả năng đáp ứng của hệ thống thoát nước, cơ sở hạ tầng đô thị. Vì vậy, việc nghiên cứu tác động của BĐKH đến ngập tại thành phố là cần thiết. Mục tiêu của nghiên cứu này nhằm đánh giá hiện trạng ngập năm 2016 và mô phỏng theo các kịch bản ngập theo RCP4.5 và RCP8.5 cho năm 2030 và 2050 , bằng cách xây dựng đường cong IDF của mưa cho hiện tại và tương lai với những thời đoạn ngắn, sử dụng mô hình MIKE FLOOD để mô phỏng ngập và từ đó thành lập bản đồ ngập cho khu vực nghiên cứu [7-20].

\section{Phương pháp nghiên cứu}

\subsection{Khu vự nghiên cứu}

Thành phố Hồ Chí Minh nằm ở phía Tây Nam vùng Đông Nam Bộ. Phía Bắc giáp tỉnh Bình Dương, Tây Bắc giáp tỉnh Tây Ninh, Đông và Đông Bắc giáp tỉnh Đồng Nai, Đông Nam giáp tỉnh Bà Rịa-Vũng Tàu và biển Đông, Tây và Tây Nam giáp tỉnh Long An và Tiền Giang. TP.HCM nằm ở hạ lưu các con sông lớn: sông Đồng Nai, sông Sài Gòn, sông Bé, ven rìa Đồng bằng sông Cửu Long. TP.HCM nằm trong vùng có khí hậu nhiệt đới gió mùa mang tính chất cận xích đạo. Lượng bức xạ dồi dào, nắng trung bình 6,13 giờ/ngày. Nhiệt độ trung bình toàn năm khoảng $28,4^{\circ} \mathrm{C}$. TP.HCM nằm trong khu vực khí hậu nhiệt đới gió mùa. Gió mùa mang một lượng lớn hơi ẩm từ phía Tây và Tây Nam. Với địa hình tự nhiên TP.HCM khá thấp cùng với các mục đích sử dụng đất khác nhau đã dẫn đến sự phân bố rõ ràng về không gian và lượng mưa, thậm chí là phụ thuộc vào sự khác nhau của các quận nội thành của Thành phố. Tổng lượng mưa TP.HCM dao động từ 1.200-2.100 mm/năm [8-12].

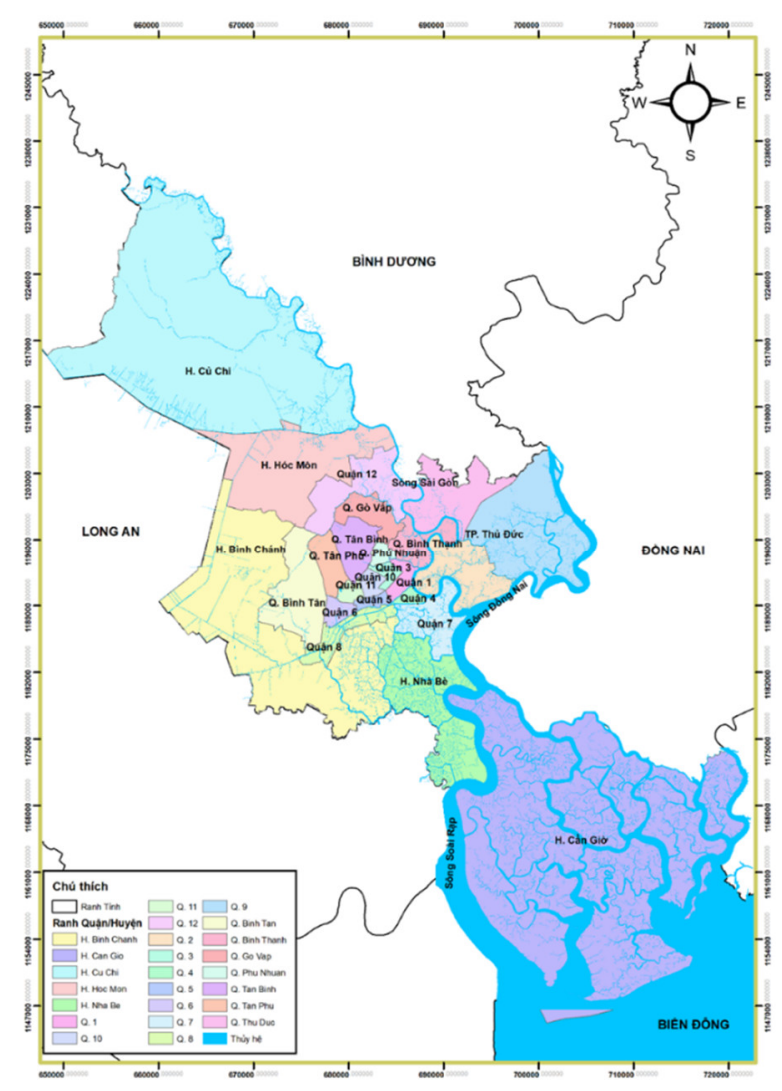

Hình 1. Bản đồ khu vực nghiên cứu. 


\subsection{Sử dụng mô hình MIKE FLOOD mô phỏng ngập}

Đối với mô phỏng và tính toán ngập lụt, trên thế giới đã có nhiều nghiên cứu, áp dụng các mô hình thủy văn, thủy lực như HEC, SWAT, WFLOW, MIKE, HEC RAS, SOBECK, MIKE,... Tại Việt Nam, có nhiều mô hình được sử dụng để tính toán lũ. Tuy nhiên, hiện nay phần mềm MIKE do Viện Thuỷ lực Đan Mạch (DHI) phát triển và được thương mại hoá bao gồm nhiều module khác nhau liên quan đến môi trường nước đã được ứng dụng rộng rãi và cho kết quả đáng tin cậy... Cụ thể là mô hình MIKE FLOOD với ưu điểm kết nối từ mạng lưới sông 1 chiều với mô hình 2 chiều cho kết quả mô phỏng diện tích ngập lụt trong thời gian ngắn, đã được ứng dụng trong nhiều nghiên cứu trên thế giới và Việt Nam [19]. Với mục đích mô phỏng ngập cho TP.HCM, nghiên cứu lựa chọn mô hình MIKE FLOOD, cho phép kết nối MIKE 11 và MIKE 21 FM một cách dễ dàng thông qua các phép kết nối bên, kết nối tiêu chuẩn. Quá trình thiết lập mô hình được thể hiện trong Hình 2.

\subsubsection{Mô hình MIKE 11}

MIKE 11 với các ứng dụng trong mô phỏng chế độ thủy lực, chất lượng nước và vận chuyển bùn cát vùng cửa sông, trong sông, hệ thống tưới, kênh dẫn và các hệ thống dẫn nước khác. Trong đó, module MIKE $11 \mathrm{HD}$ mô tả quá trình thủy lực dựa trên phương trình liên tục và phương trình động lượng (hệ phương trình Saint-Venant), được giải theo lược đồ sai phân hữu hạn 6 điểm ẩn (Abbott-Inoescu). Các bước thiết lập mô hình gồm xây dựng mạng lưới sông, mặt cắt sông, xác định biên (thượng nguồn, hạ nguồn) và các thông số mô hình. Trong nghiên cứu này, mạng lưới sông...[21]. Cụ thể trong nghiên cứu này MIKE 11 được sử dụng để mô phỏng hệ thống thủy lực mạng sông Sài Gòn-Đồng Nai với các nhánh sông chính như: sông Sài Gòn, sông Đồng Nai, sông Thị Tính, sông Vàm Cỏ Đông, sông Lòng Tàu, sông Soài Rạp...

\subsubsection{Mô hình MIKE 21 FM}

MIKE 21 Flow Model FM dựa trên lưới tính linh hoạt, phối hợp giữa ô lưới hình tam giác và ô lưới hình chữ nhật, được phát triển cho các ứng dụng trong môi trường hải dương học, ven biển và cửa sông, có thể được áp dụng cho các nghiên cứu về lũ lụt trên đất liền. Gồm các module ELOS, HD, MT, PT, ST, TR; trong đó, module thủy động lực cung cấp cơ sở cho việc tính toán các quá trình được thực hiện trong nhiều module khác hoặc cũng có thể được sử dụng độc lập. Module này được xây dựng dựa trên phương trình Navier-Stokes 2, 3 chiều trung bình với hệ số Reynolds không nén kết hợp độ sâu với các giả định Boussinesq và áp suất thủy tĩnh. Sự rời rạc không gian của các phương trình cơ bản được thực hiện bằng phương pháp thể tích hữu hạn ô trung tâm với sơ đồ sai phân hiện [22-26]. Cụ thể trong nghiên cứu mô hình MIKE $21 \mathrm{FM}$ sử dụng để tính toán địa hình từ lưới tính Mesh và địa hình Lidar có độ phân giải $5 \mathrm{~m}$ x 5m "nguồn: Sở khoa học công nghệ TP.HCM" bên cạnh đó là bản đồ sử dụng đất gồm chủ yếu các loại đất ở, đất giao thông, đất cây xanh được số hóa vào để hoàn thiện dữ liệu địa hình tính toán trong mô hình MIKE $21 \mathrm{FM}$, mô hình sử dụng lưới tính tam giác với 13339 nút tính toán và 23782 phần tử.

\subsubsection{Kết nối mô hình $1 \mathrm{D}$ và $2 \mathrm{D}$ vào mô hình MIKE FLOOD}

Phạm vi tính toán từ Hồ Dầu Tiếng trên sông Sài Gòn, Hồ Trị An trên sông Đồng Nai, đến Ngã Ba Đèn Đỏ hợp lưu sông Nhà Bè và qua sông Soài Rạp cùng hệ thống sông rạch khu vực Cần Giờ ra biển, bên cạnh còn có hệ thống sông Vàm Cỏ Đông lấy từ trạm thủy văn Gò Dầu, trên sông Vàm Cỏ Tây lấy từ trạm thủy văn Tân An. Vì vậy, các biên tính toán bao gồm:

MIKE 11 được liên kết với MIKE 21FM bằng công cụ Link River Branch to Mike 21 sử dụng liên kết Lateral để liên kết các sông trong hệ thống thủy lực MIKE 11 vào địa hình khu vực TP.HCM [27-30]. 
Biên thượng nguồn: biên mực nước theo giờ tại các trạm: Tân An (sông Vàm Cỏ Tây), Gò Dầu (sông Vàm Cỏ Đông) từ 0:00 ngày 01/01/2016 đến 23:00 ngày 30/11/2016 và biên lưu lượng theo ngày từ 01/01/2016 đến 30/11/2016 của các hồ: Dầu Tiếng (sông Sài Gòn) và Trị An (sông Đồng Nai).

Biên hạ nguồn: sử dụng số liệu mực nước quan trắc tại trạm Vũng Tàu từ 0:00 ngày 01/01/2016 đến 23:00 ngày 30/11/2016.

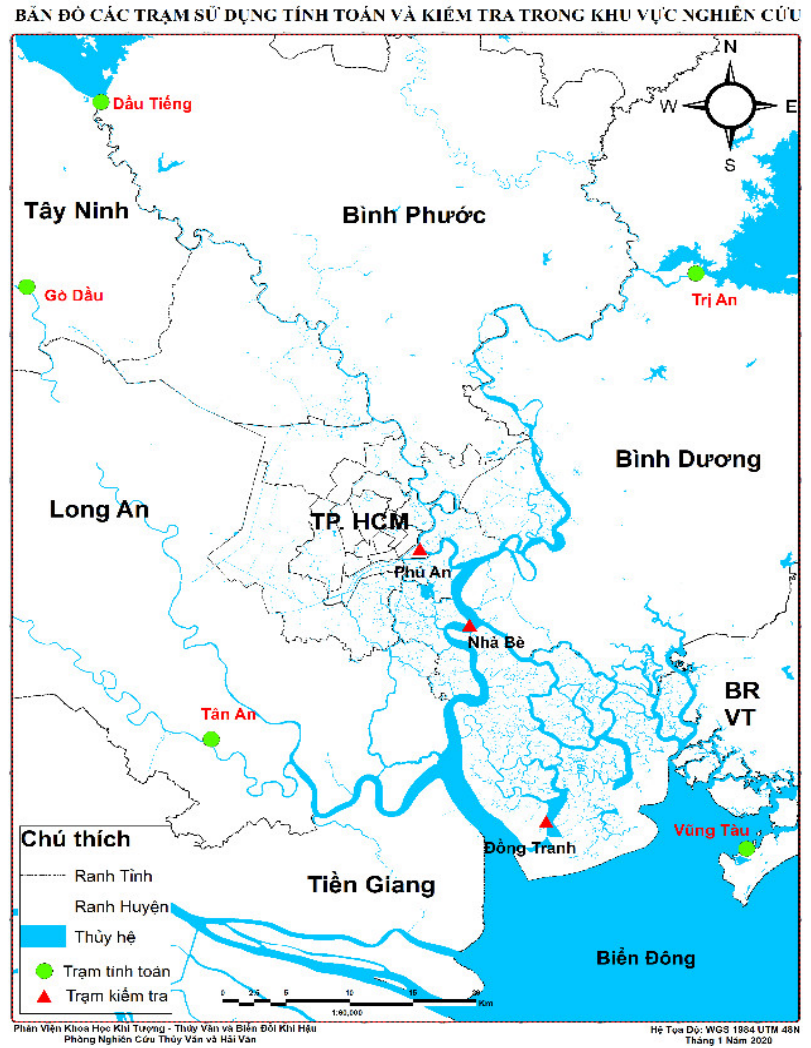

Hình 2. Bản đồ các trạm tính toán và kiểm tra tại khu vực nghiên cứu.

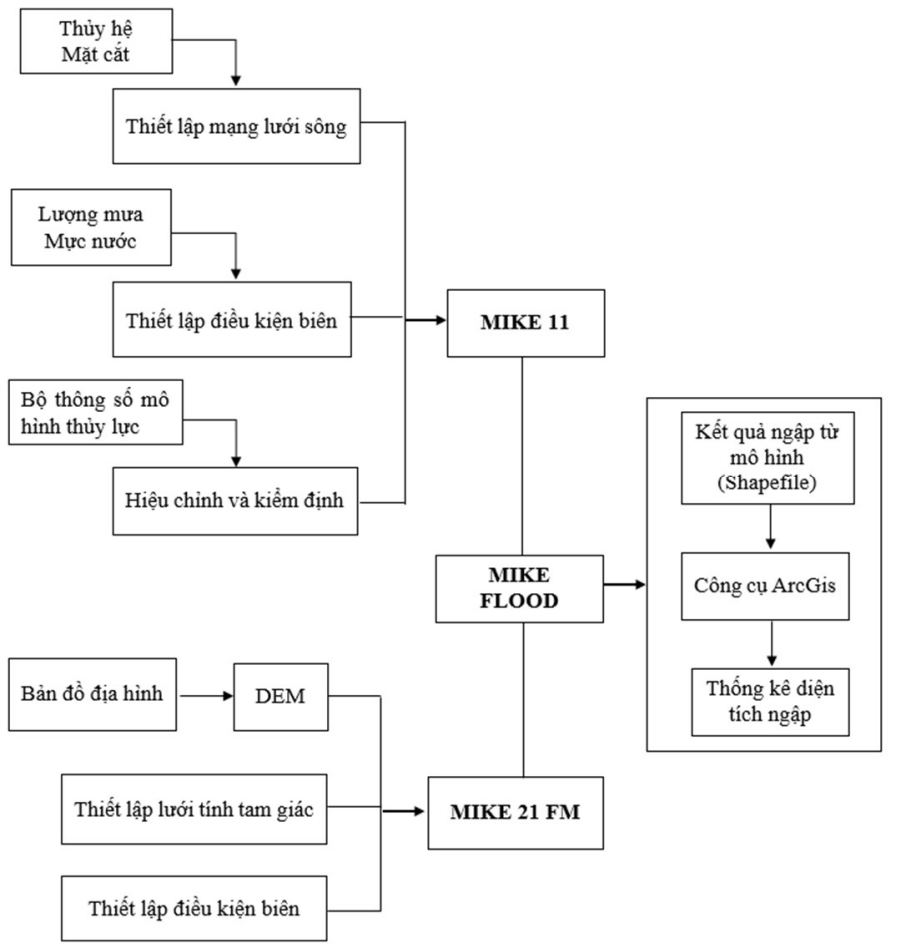

Hình 3. Quá trình thiết lập mô hình mô phỏng ngập. 


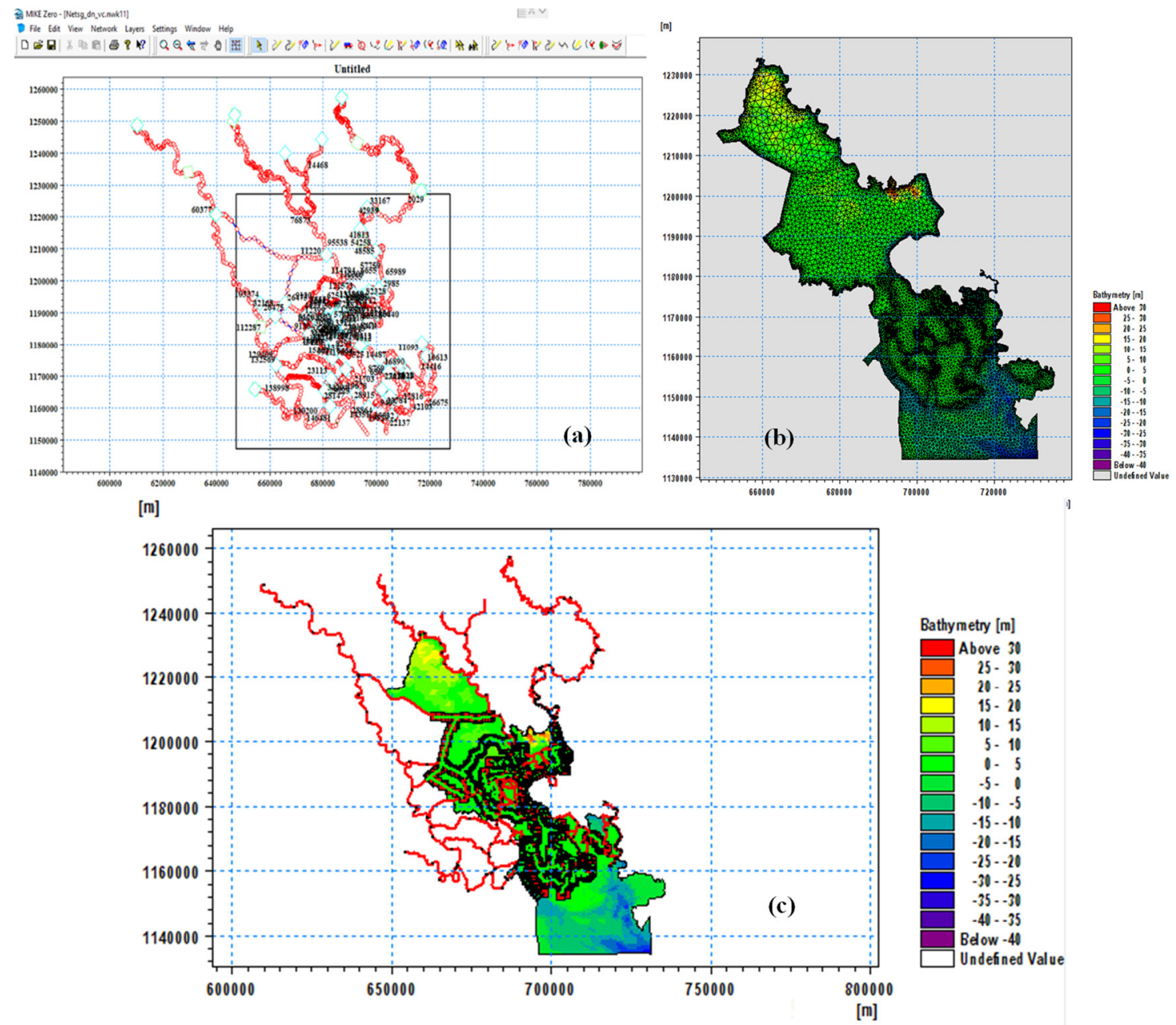

Hình 4. (a) Sơ đồ thủy lực mạng sông Sài Gòn-Đồng Nai; (b) Dữ liệu địa hình trong mô hình MIKE 21 FM; (c) Liên kết MIKE 11 HD và MIKE 21 FM.

MIKE 11 được kết nối với MIKE 21FM bằng công cụ kết nối nhánh sông với MIKE 21 (Link river branch to MIKE 21); sử dụng kết nối bên (Lateral) để kết nối bờ phải và bờ trái các nhánh sông trong hệ thống thủy lực MIKE 11 vào địa hình khu vực TP.HCM trong MIKE 21 với số ô lưới kết nối (Hình $4 \mathrm{a}-4 \mathrm{c})$.

\subsection{Mô hìn mưa thiết kế}

Trong nghiên cứu này sử dụng mưa thời đoạn $3 \mathrm{~h}$ để tính toán ngập lụt vì có đặc điểm cho trận mưa đặc trung ở khu vực TP.HCM, bên cạnh đó sử dụng phương pháp cường độ mưa tức thời để xác định đỉnh mưa cho trận mưa đại biểu và theo các kịch bản biển đổi khí hậu khác nhau, từ đó dựa vào nghiên cứu về phân bố mưa của TP. Hồ Chí Minh [14] [18] nhằm xác định hệ số mưa trước đỉnh phục vụ xây dựng biểu đồ mưa thiết kế.

\subsection{Xây dựng kịch bản tính toán ngập}

Trong nghiên cứu này đề xuất 5 kịch bản tính toán ảnh hưởng của tổ hợp mưa, triều và lũ đến tình hình ngập trên địa bàn TP.HCM. Các kịch bản này bao gồm việc đánh giá ngập với điều kiện hiện tại và kịch bản có xét đến yếu tố đô thị hoá và BĐKH. Đối với việc đô thị hoá, sử dụng dữ liệu đô thị hoá đến năm 2025 theo quy hoạch phát triển không gian đô thị. Đối với $\mathrm{BĐKH}$, sử dụng kịch bản $\mathrm{BĐKH}$ của Bộ Tài nguyên và Môi trường ban hành năm 2016 [20]. Kịch bản hiện trạng xét trong trường hợp là kịch bản nền để so sánh. Các kịch bản cụ thể như sau: 
Bảng 1. Các kịch bản tính toán ngập.

\begin{tabular}{|c|c|c|c|c|c|c|c|}
\hline STT & Kịch bản & Ký hiệu & Mưa & Triều & Lũ & Địa hình & ВĐКН \\
\hline 1 & Hiện trạng & Hientrang & $\begin{array}{l}\text { Hiện } \\
\text { trạng }\end{array}$ & $\begin{array}{l}\text { Hiện } \\
\text { trạng }\end{array}$ & $\begin{array}{l}\text { Hiện } \\
\text { trạng }\end{array}$ & Hiện trạng & Không xét \\
\hline 2 & $\begin{array}{c}\text { Đến năm } 2050 \text { có xét } \\
\text { BĐKH-RPC4.5 }\end{array}$ & 2050RPC4.5 & $50 \%$ & $50 \%$ & $50 \%$ & Quy hoạch & $\begin{array}{l}2050 \mathrm{R} \\
\mathrm{PC} 4.5\end{array}$ \\
\hline 3 & $\begin{array}{c}\text { Đến năm } 2050 \text { có xét } \\
\text { BĐKH-RPC } 8.5\end{array}$ & 2050RPC 8.5 & $50 \%$ & $50 \%$ & $50 \%$ & Quy hoạch & $\begin{array}{l}2050 \mathrm{R} \\
\mathrm{PC} 8.5\end{array}$ \\
\hline 4 & $\begin{array}{c}\text { Đến năm } 2030 \text { có xét } \\
\text { BĐKH-RPC4.5 }\end{array}$ & 2030RPC4.5 & $20 \%$ & $20 \%$ & $20 \%$ & Quy hoạch & $\begin{array}{l}2030 \mathrm{R} \\
\mathrm{PC} 4.5\end{array}$ \\
\hline 5 & $\begin{array}{c}\text { Đến năm } 2030 \text { có xét } \\
\text { BĐKH-RPC8.5 }\end{array}$ & 2030RPC 8.5 & $20 \%$ & $20 \%$ & $20 \%$ & Quy hoạch & $\begin{array}{l}2030 \mathrm{R} \\
\mathrm{PC} 8.5\end{array}$ \\
\hline
\end{tabular}

Ngoài kịch bản lũ ở thượng nguồn, nước biển dâng ở hạ nguồn, nghiên cứu còn xét đến yếu tố mưa nhập bên ở khu vực nghiên cứu. Bằng việc lựa chọn trận mưa đại biểu có thời đoạn 3h vào ngày 26/09/2016 gây ngập nặng nề TP.HCM cho kịch bản hiện trạng. Chúng tôi tiến hành thành lập biểu đồ mưa thiết kế dựa vào đường IDF theo phương pháp mưa đại biểu, từ đó chúng tôi lựa chọn kịch bản mưa thời đoạn trong tương lai theo các kịch bản IDF. Biểu đồ mưa thiết kế theo các tần suất cụ thể được trình bày như Hình $5 \mathrm{a}-5 \mathrm{~b}$.

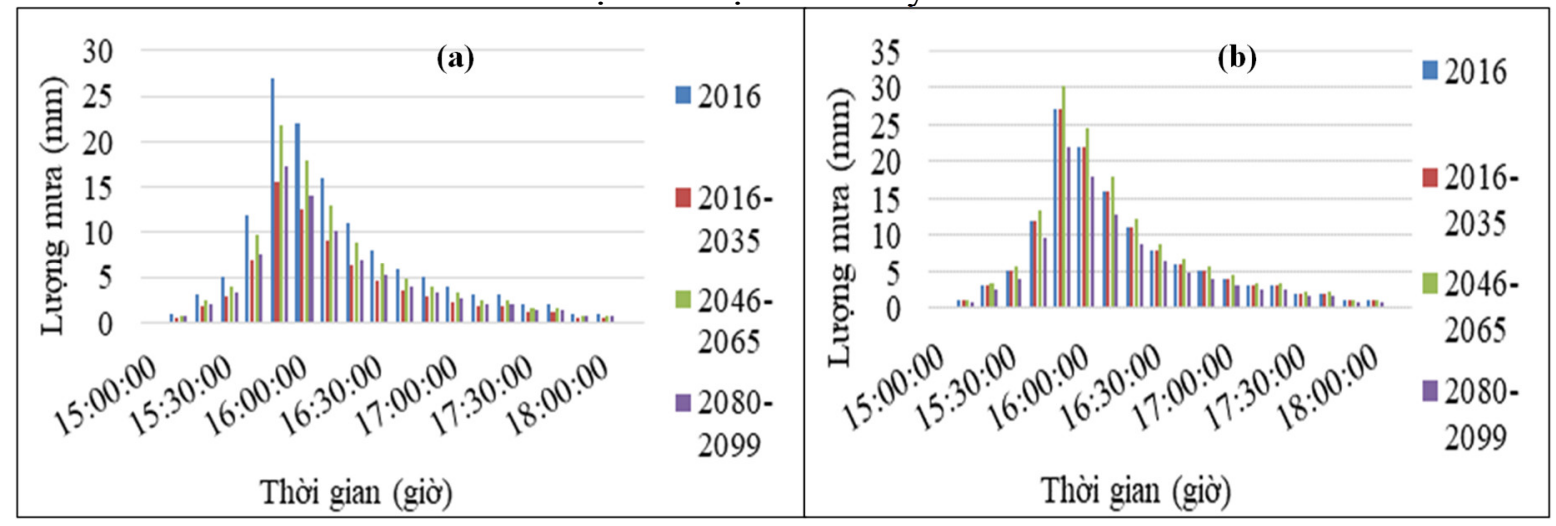

Hình 5. (a) Biểu đồ mưa thiết kế tần suất 50\%; (b) Biểu đồ mưa thiết kế tần suất 20\%.

\section{Kết quả nghiên cứu và thảo luận}

\subsection{Kết quả hiệu chinh-kiểm định mô hình}

Hiệu chỉnh mô hình qua hệ số nhám Manning được chọn trong khoảng 12-45 $\left(\mathrm{m}^{1 / 3} / \mathrm{s}\right)$ tùy vào đoạn sông. Mô hình thủy lực được hiệu chỉnh và kiểm định ở trạm thủy văn Phú An, Nhà Bè và Đồng Tranh.

Thời gian hiệu chỉnh mô hình từ 9:00 ngày 28/09/2015 đến 09:00 giờ ngày 30/09/2015, sau khi hiệu chỉnh bộ thông số tính toán mô hình phù hợp, mô hình được kiểm định lại từ 9:00 ngày 17/09/2016 đến 9:00 ngày 19/09/2016.

Kết quả tính toán mực nước được hiệu chỉnh và kiểm định cho giá trị tương quan với số liệu thực đo đạc trên 0,95 ở trạm Phú An, Nhà Bè và Đồng Tranh (Hình 6a-6c). Như vậy, cơ sở dữ liệu đầu vào mô hình MIKE FLOOD đã xây dựng đủ tin cậy để áp dụng tính toán mô phỏng ngập cho khu vực nghiên cứu. 


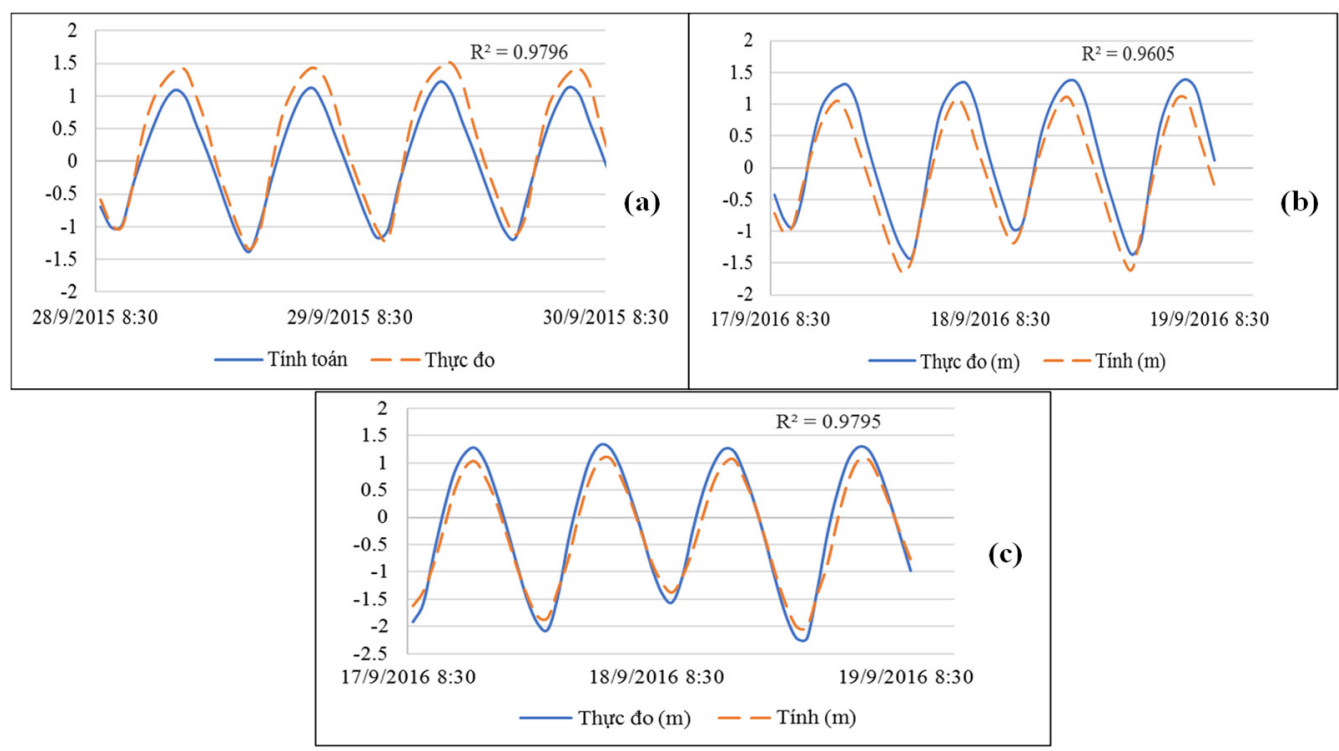

Hình 6. (a) Kết quả hiệu chỉnh mực nước tại Phú An tháng 9/2015; (b) Kết quả kiểm định mực nước Nhà Bè tháng 9/2016; (c) Kết quả kiểm định mực nước Đồng Tranh tháng 9/2016.

\subsection{Kết quả tính toán mực nước trên sông Sài Gòn}

Nghiên cứu đã tính toán thủy lực cho khu vực thành phố từ 1/10-30/11/2016. Từ mục tiêu phục vụ tính toán ngập, mực nước tháng 10 (tháng có mực nước cao nhất năm 2016) được sử dụng để trình bày kết quả đặc trưng mực nước tại các trạm Thị Tính, Nhà Bè, Tam Thôn Hiệp. Trong thời gian 01/10-31/10, mực nước tại ba nhánh sông Sài Gòn là Nhà Bè, Tam Thôn Hiệp và ngã ba sông Thị Tính khá cao, cao nhất ở trạm ngã ba Thị Tính khoảng $1,731 \mathrm{~m}$ (Bảng 2). Những thời điểm này, khả năng bị ngập là rất cao ở một số quận huyện, vì địa hình tại khu vực nghiên cứu thuộc vùng trung bình và có nhiều điền trũng.

Bảng 2. Đặc trưng mực nước tính toán (m) năm 2016.

\begin{tabular}{cccc}
\hline Đặc trưng $(\mathbf{m})$ & Ngã ba Thị Tính & Nhà Bè & Tam Thôn Hiệp \\
\hline Min & $-2,249$ & $-2,117$ & $-2,093$ \\
TB & $-0,061$ & $-0,078$ & $-0,117$ \\
Max & 1,731 & 1,62 & 1,369 \\
\hline
\end{tabular}

Bảng 3. Đặc trưng mực nước tính toán (m) theo kịch bản RCP4.5 cho năm 2030 .

\begin{tabular}{cccc}
\hline Đặc trưng (m) & Ngã ba Thị Tính & Nhà Bè & Tam Thôn Hiệp \\
\hline Min & $-2,068$ & $-1,996$ & $-2,000$ \\
TB & 0,102 & 0,033 & $-0,013$ \\
Max & 1,717 & 1,709 & 1,498 \\
\hline
\end{tabular}

Bảng 4. Đặc trưng mực nước tính toán (m) theo kịch bản RCP4.5 cho năm 2050.

\begin{tabular}{cccc}
\hline $\begin{array}{c}\text { Đặc trưng } \\
(\mathbf{m})\end{array}$ & Ngã ba Thị Tính & Nhà Bè & Tam Thôn Hiệp \\
\hline Min & $-1,752$ & $-1,647$ & $-1,637$ \\
TB & 0,448 & 0,423 & 0,371 \\
Max & 2,218 & 2,102 & 1,892 \\
\hline
\end{tabular}


Bảng 5. Đặc trưng mực nước tính toán (m) theo kịch bản RCP8.5 cho năm 2030.

\begin{tabular}{cccc}
\hline Đặc trưng $(\mathbf{m})$ & Ngã ba Thị Tính & Nhà Bè & Tam Thôn Hiệp \\
\hline Min & $-2,282$ & $-2,013$ & $-2,014$ \\
TB & 0,118 & 0,033 & $-0,013$ \\
Max & 1,688 & 1,722 & 1,483 \\
\hline
\end{tabular}

Bảng 6. Đặc trưng mực nước tính toán (m) theo kịch bản RCP8.5 cho năm 2050.

\begin{tabular}{cccc}
\hline Đặc trưng $(\mathbf{m})$ & Ngã ba Thị Tính & Nhà Bè & Tam Thôn Hiệp \\
\hline Min & $-1,742$ & $-1,464$ & $-1,451$ \\
TB & 0,708 & 0,619 & 0,563 \\
Max & 2,254 & 2,270 & 2,080 \\
\hline
\end{tabular}

Từ kết quả tính toán theo kịch bản RCP4.5 cho năm 2030, triều cường đạt giá trị cao nhất vào ngày $17 / 10 / 2030$. Kịch bản $\mathrm{RCP} 4.5$ cho năm 2050 , triều cường cao nhất vào ngày 18/10/2050; Kịch bản RCP8.5 cho năm 2050, triều cường cao nhất vào ngày $17 / 10 / 2050$, cho năm 2030, triều cường cao nhất vào ngày 18/10/2030 (Bảng 3-6).

\subsection{Kết quả tính toán ngập cho khu vực nghiên cưu}

Theo số liệu thống kê năm 2016, trên toàn TP.HCM có khoảng 40 điểm ngập. Các điểm ngập tập trung ở các quận huyện ngoại thành như huyện Bình Chánh, Nhà Bè, quận Thủ Đức, quận 9 , và quận 2 với độ sâu trung bình khoảng từ $0,3-0,4 \mathrm{~m}$ và nhiều điểm ngập trong các quận nội thành như quận Bình Thạnh, quận 12, Tân Bình, Gò Vấp, quận 11 và một đoạn đường Nguyễn Hữu Cảnh, quận 1.

Kết quả mô phỏng ngập được so sánh với số liệu thống kê các điểm ngập, từ Trung tâm Điều hành chương trình chống ngập nước TP.HCM cho thấy: Các kết quả tính toán mô phỏng ngập từ mô hình khá phù hợp với giai đoạn hiện trạng năm 2016 (Hình 7a), các tuyến đường ngập trong hiện trạng năm 2016 cho kết quả khá chính xác, chênh lệch sai số giữa hiện trạng thực đo và kết quả ngập ở một số đường lần lượt là: đường Nguyễn Hữu Cảnh khoảng 0,05 $\mathrm{m}$, đường Quốc Hương, Nguyễn Văn Hưởng khoảng $0,03 \mathrm{~m}$, Quốc lộ $1 \mathrm{~A}$ và Huỳnh Tấn Phát lần lượt là $0,05 \mathrm{~m}$. Diện tích ngập cao nhất trong nghiên cứu này dựa vào tỷ lệ giữa diện tích ngập so với diện tích tự nhiên của toàn quận, huyện. Tương ứng quận, huyện nào có tỷ lệ ngập cao thì có diện tích ngập cao. Các kết quả nghiên cứu thực hiện mô phỏng ngập tại khu vực nghiên cứu ở các kịch bản tương lai cho năm 2030, năm 2050; theo hai kịch bản RCP4.5 và RCP8.5.

Kết quả mô phỏng ngập theo các kịch bản được cho thấy:

+ Đối với năm 2030 , cả hai kịch bản RCP4.5 và RCP8.5 mức độ ngập tăng lên so với kết quả mô phỏng năm 2016. Tổng diện tích ngập trong hai kịch bản này là 4056,3 ha (chiếm $1,96 \%$ diện tích thành phố), cao hơn so với kết quả hiện trạng 2016 khoảng 2465,2 ha (tương ứng với tỷ lệ ngập là 1,19\%) (Hình 7b-7c). 

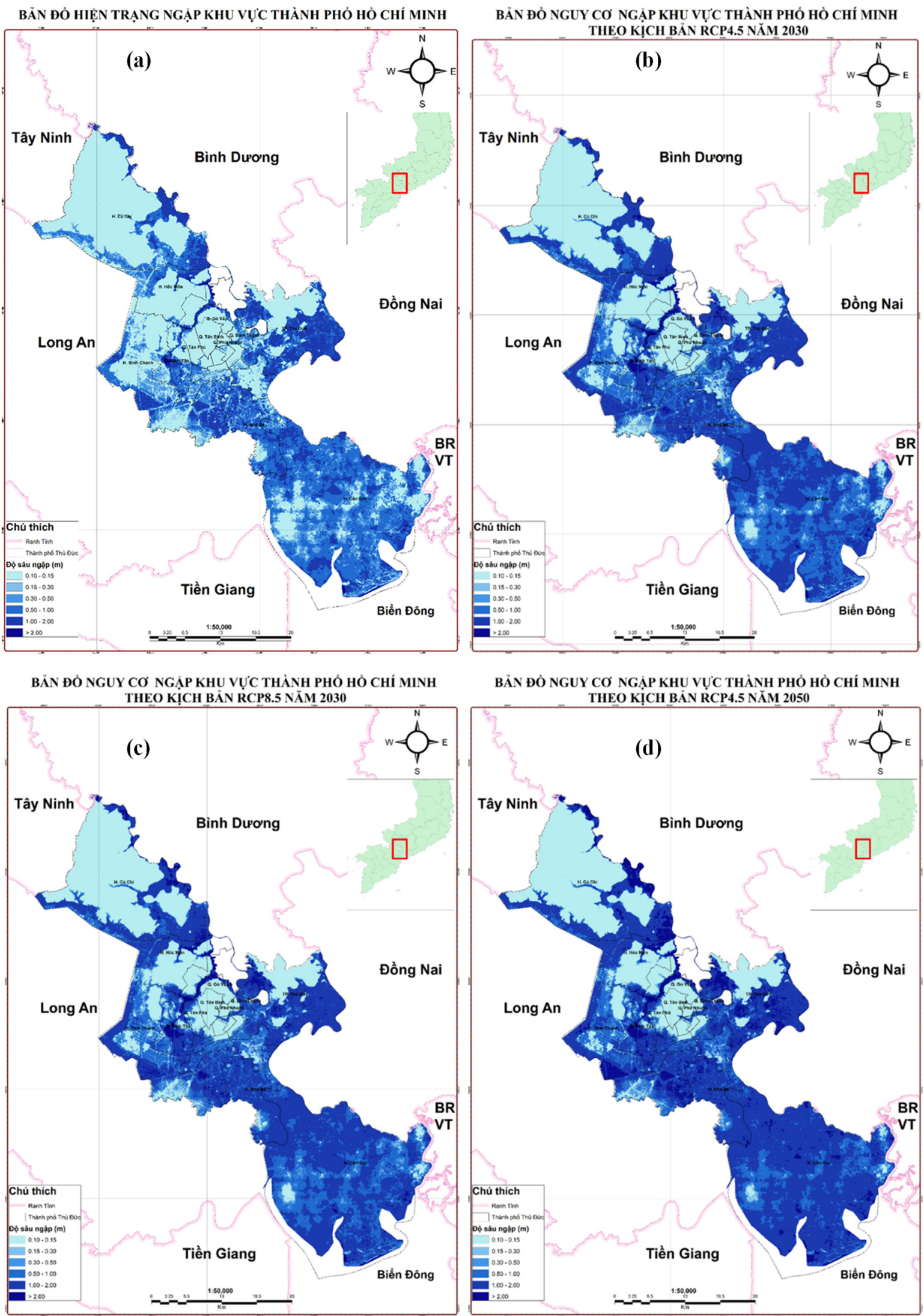

Hình 7. (a) Bản đồ ngập cao nhất cho TP.HCM theo hiện trạng năm 2016; (b) Bản đồ ngập cao nhất cho TP.HCM năm 2030 theo kịch bản RCP 4.5; (c) Bản đồ ngập cao nhất cho TP.HCM năm 2030 theo kịch bản RCP 8.5; (d) Bản đồ ngập cao nhất cho TP.HCM năm 2050 theo kịch bản RCP 4.5. 


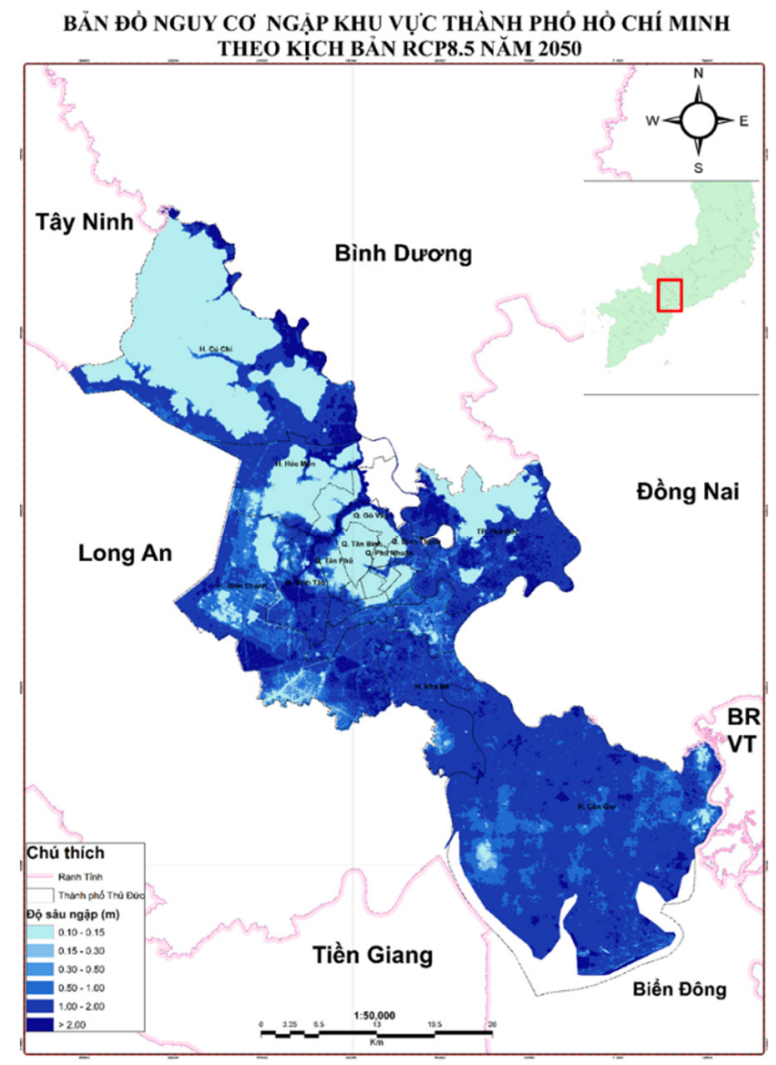

Hình 8. Bản đồ ngập cao nhất cho TP.HCM năm 2050 theo kịch bản RCP 8.5.

Bảng 7. Diện tích ngập của TP.HCM theo các kịch bản.

\begin{tabular}{cccccc}
\hline TT & Kịch bản & Năm & $\begin{array}{c}\text { Diện tích ngập } \\
\text { (ha) }\end{array}$ & Tỷ lệ ngập (\%) & $\begin{array}{c}\text { Quận/huyện ngập } \\
\text { nhiều nhất }\end{array}$ \\
\hline 1 & Hiện trạng & 2016 & 1591,1 & 0,77 & Quận 9 \\
2 & & 2030 & 4056,3 & 1,96 & H. Cần Giờ \\
3 & RCP 4.5 & 2050 & 8757,02 & 4,27 & H. Cần Giờ \\
4 & & 4056,3 & 1,96 & H. Cần Giờ \\
5 & RCP 8.5 & 2030 & 9039,91 & 4,38 & H. Cần Giờ \\
\hline
\end{tabular}

+ Kịch bản ngập đến năm 2050 với kịch bản RCP4.5, các kết quả mô phỏng cho thấy, diện tích ngập và mức ngập tăng lên. Ở kịch bản này, tổng diện tích ngập khoảng 8757,02 ha (chiếm 4,27\% diện tích toàn thành phố) cao hơn so với kết quả hiện trạng 2016 khoảng 7165,9 ha (tỷ lệ ngập tương ứng chiếm $3,29 \%$ so với diện tích ngập hiện trạng và chiếm $4,27 \%$ so với diện tích toàn thành phố) (Hình $7 \mathrm{~d}$ ).

+ Đối với kịch bản RCP8.5 năm 2050 thì hơn 4,38\% diện tích của TP.HCM có nguy cơ bị ngập, với tổng diện tích ngập khoảng 9039,91 ha. So sánh với kết quả ngập hiện trạng năm 2016 thì trong kịch bản này, tồng diện tích ngập tăng 7448,8 ha và tỷ lệ ngập tăng tương ứng là $3,61 \%$ (Hình 8 ).

Theo các kết quả nghiên cứu, huyện Cần Giờ, Bình Chánh, Nhà Bè và các quận $9,8,7$, 2 là những quận, huyện chịu ảnh hưởng nặng bởi ngập ở cả thời điểm hiện tại và trong tương lai.

\section{Kết luận}

Nghiên cứu đã đánh giá các diễn biến của chế độ mực nước trên sông Sài Gòn-Đồng Nai theo hiện trạng 2016 và các kịch bản $\mathrm{BĐKH}$ được thiết kế. Các kết quả tính toán cho giai 
đoạn ngập giai đoạn năm 2016 với tổng diện tích ngập của TP.HCM khoảng 1591,1 ha chiếm $0,77 \%$ diện tích khu vực nghiên cứu. Theo các mô phỏng ngập theo các kịch bản RCP4.5 năm 2030 có diện tích ngập là 4056,3 ha năm 2050 là 8757,02 ha, tỉ lệ ngập lần lượt là 1,96\% và 4,27\%. Tương tự kịch bản RCP 8.5 năm 2030 có tiện tích ngập là 4956,3 ha, năm 2050 là 9039,91 ha có tỉ lệ ngập lần lượt là $1,96 \%$ và $4,38 \%$, vùng chịu ảnh hưởng ngập nặng nhất của $\mathrm{BĐKH} \mathrm{là} \mathrm{các} \mathrm{quận,} \mathrm{huyện} \mathrm{khu} \mathrm{vực} \mathrm{phía} \mathrm{Nam-Tây} \mathrm{Nam} \mathrm{và} \mathrm{Đông} \mathrm{Nam} \mathrm{thành} \mathrm{phố} \mathrm{(thuộc}$ các quận $9,8,7$ và các huyện Bình Chánh, Nhà Bè, Cần Giờ), do đây là những vùng thấp trũng, độ cao trung bình trên dưới $1 \mathrm{~m}$ và cao nhất $2 \mathrm{~m}$, thấp nhất $0,5 \mathrm{~m}$. Báo cáo này còn có một số hạn chế là chưa đưa hệ thống thoát nước và công trình cơ sở hạ tầng vào để tính toán (cống, hầm ga, cửa xả và các cống, đê biển, đê ngăn triều). Các yếu tố động lực khác có liên quan như sự nâng hạ địa chất, sự thay đổi địa hình, sụt lún đất do khai thác nước ngầm, thay đổi đường bờ biển, ảnh hưởng của thủy triều, nước dâng do bão, nước dâng do gió mùa,... chưa được xét đến trong các kịch bản này. Các kết quả nghiên cứu trên chỉ là kết quả nghiên cứu ban đầu, độ tin cậy chưa cao, cần được tiếp tục nghiên cứu thêm.

Đóng góp của tác giả: Xây dựng ý tưởng nghiên cứu: N.V.H.; Lựa chọn phương pháp nghiên cứu: N.V.H., N.P.Đ.; Xử lý số liệu: N.P.Đ.; Viết bản thảo bài báo: N.V.H., N.P.Đ.; Chỉnh sửa bài báo: N.V.H., N.P.Đ.

Lời cảm ơn: Nghiên cứu này được thực hiện dưới sự tài trợ của đề tài nghiên cứu khoa học "Xây dựng mô hình dự báo, cảnh báo và quản lý ngập cho đô thị thông minh tại Thành phố Hồ Chí Minh", Sở KHCN TP.HCM và dự án "Xây dựng kế hoạch hành động ứng phó với BĐKH giai đoạn 2020-2030, tầm nhìn 2050 cho thành phố HCM”, Sở TNMT TP.HCM.

Lời cam đoan: Tập thể tác giả cam đoan bài báo này là công trình nghiên cứu của tập thể tác giả, chưa được công bố ở đâu, không được sao chép từ những nghiên cứu trước đây; không có sự tranh chấp lợi ích trong nhóm tác giả.

\section{Tài liệu tham khảo}

1. IPCC. The Physical Science Basis. Contribution of Working Group I to the Fourth Assessment Report of the Intergovernmental Panel on Climate Change, 2007.

2. IPCC. The Physical Science Basis. Contribution of Working Group I to the Fifth Assessment Report of the Intergovernmental Panel on Climate Change, 2013.

3. Global facility for Disaster Redution and Recovery. Country Profile Vietnam, 2015

4. ADB-ICEM. Ho Chi Minh City Adaptation Climate Changes, 2010.

5. Adger, Niel. Social Vulnerability to Climate Change and Extremes in Coastal Vietnam, 1999. World Development 27 (2): 249-69. doi:10.1016/S0305750X(98)00136-3.

6. Asian Development Bank. Ho Chi Minh City Adaptation to climate change Summary report, 2010.

7. IPCC. Climate Change 2014: Impacts, Adaptation, and Vulnerability. Part B: Regional Aspects, 2014.

8. Phân Viện Khí tượng Thủy văn và Biến đổi khí hậu. Nghiên cứu xây dựng cơ sở dữ liệu các đặc trưng khí tượng thủy văn phục vụ phòng chống ngập úng khu vực TP. HCM, 2008.

9. Phân viện Khí tượng Thủy văn và Biến đổi khí hậu. Nghiên cứu và xây dựng mô hình đánh giá tác động của biến đổi khí hậu đến các yếu tố tự nhiên, con người kinh tế - xã hội Tp.HCM, 2011.

10. Phân viện Khoa học Khí tượng Thủy văn và Biến đổi khí hậu. Nghiên cứu tính toán ngập úng lưu vực quận 12 - Thành phố Hồ Chí Minh bằng mô hình MIKE FLOOD, 2015. 
11. Hoàng, T.T.; Nam, B.C.; Thịnh, N.N. Nghiên cứu tính toán mưa rào dòng chảy hạ lưu sông Sài Gòn làm đầu vào cho bài toán chống ngập. Tạp chí Khí tượng Thưy văn 2012, 622, 17-21.

12. Phân viện KTTV\&BĐKH. Xây dựng, cập nhật kế hoạch hành động ứng phó với BĐKH giai đoạn 2021-2030, tầm nhìn đến 2050 trên địa bàn TPHCM. Dự án Sở TNMT TP.HCM, 2020.

13. Tuấn, L.N. Nghiên cứu, cập nhật các kịch bản BĐKH của thành phố Hồ Chí Minh theo phương pháp luận và kịch bản mới của ủy ban liên chính phủ về BĐKH (IPCC) và Bộ Tài nguyên và Môi trường. Đề tài Sở Khoa học và Công nghệ TPHCM, 2017.

14. Việt, L.V. Xây dựng cơ sở dữ liệu mưa cho TP. HCM. Phân Viện Khoa học Khí tượng Thủy văn và Biến đổi khí hậu, 2008.

15. Hiếu, T.V. Báo cáo tổng kết đề tài nghiên cứu cấp Thành phố: Nghiên cứu phương pháp phân vùng ngập và thoát nước đô thị-Nội thành TP.HCM, 2003.

16. Sâm, L. Báo cáo Đề tài NCKH độc lập cấp nhà nước: Nghiên cứu đề xuất các giải pháp chống ngập cho thành phố Hồ Chí Minh. Viện Khoa học Thủy lợi Miền nam, 2010.

17. Tuấn, L.N; Kim, T.T; Phùng, N.K. Nguy cơ ngập do triều tại Thành phố Hồ Chí Minh trong bối cảnh biến đổi khí hậu và nước biển dâng. Tạp chí Phát triển Khoa học \& Công nghệ: Chuyên san Khoa hoc Tư nhiên 2018, 2(6),182-191.

18. Khiêm, M.V. Đề tài cấp Thành phố: Nghiên cứu khả năng đáp ứng của hệ thống thoát nước trên địa bàn thành phố Hồ Chí Minh trong điều kiện biến đổi khí hậu, 20172019.

19. Bình, H.T; Anh, T.N; Khá, Đ.Đ. Úng dụng mô hình MIKE FLOOD tính toán ngập lụt hệ thống sông Nhật Lệ tỉnh Quảng Bình. Tạp chí Khoa hoc ĐHQGHN, Khoa học Tư nhiên và Công nghẹ 2010, 26(3S), 34-42.

20. Bộ Tài Nguyên và Mồi Trường. Kịch bản biến đổi khí hậu và nước biển dâng cho Việt Nam, 2016.

21. Mirhosseini, G.; Srivastava, P.; Fang, X. Developing Rainfall Intensity-DurationFrequency Curves for Alabama under Future Climate Scenarios Using Artificial Neural Networks. J. Hydrol. Eng. 2014, 19(11), 04014022. https://doi.org/10.1061/(ASCE)HE.1943-5584.0000962.

22. Afrin, S.; Islam, M.M.; Rahman, M.M. Development of IDF Curve for Dhaka City Based on Scaling Theory under Future Precipitation Variability Due to Climate Change. Int. J. Environ. Sci. Dev. 2015, 6(5), 332-335.

23. Wang, X.; Huang, G.; Liu, J. Projected increases in intensity and frequency of rainfall extremes through a regional climate modeling approach. J. Geophys. Res. Atmos. 2014, 119, 271-286. https://doi.org/10.1002/2014JD022564.

24. Bart, V.D.H.; Peter, S.; Albert, K.T. Climate Change scenarios for the $21^{\text {st }}$ Century - A Netherlands perspective. Scientific Report WR2014-01, KNMI, De Bilt, the Netherlands, 2014.

25. Zhou, Q.; Su, J.; Arnbjerg-Nielsen, K.; Ren, Y.; Luo, J.; Ye, Z.; Feng, J. A GISBased Hydrological Modeling Approach for Rapid Urban Flood Hazard Assessment. Water 2021, 13, 1483. https://doi.org/10.3390/w13111483.

26. IPCC Fifth Assessment Report. Climate Change 2013 - The Physical Science Basis. Cambridge University Press, Cambridge, UK, 2013, pp. 1535.

27. DHI. Mike 11 - HD User Manual, 2014.

28. DHI. MIKE FLOOD User Guide, 2014.

29. DHI. Mike Flood modelling of river flooding step by step tranining guide, 2014.

30. DHI. MIKE 21 \& MIKE 3 Flow Model FM. Hydrodynamic Module, Scientific documentation, 2014. 


\title{
Studying on building the flood scenarios in ho chi minh city by the impacts of climate change
}

\section{Nguyen Van Hong ${ }^{*}$, Nguyen Phuong Dong ${ }^{1}$}

${ }^{1}$ Sub-Institute of HydroMeteorology and Climate Change; nguyenvanhong79@gmail.com; donghai930t110@gmail.com

\begin{abstract}
In the recent years, due to the impact of extreme climate, the characteristics of rain and tide in Ho Chi Minh City has changed. That has greatly affected the flooding of the city, causing damage as well as greatly impact on the socio-economic activity of the city's people. Therefore, this study on the climate change impacts to flood in the city is really necessary. In this study, Using the MIKE FLOOD model to assess the impact of inundation in HCMC under the influence of climate change (floods upstream in rivers, frequent extreme precipitation and sea level rise in downstream of Sai Gon and Dong Nai rivers) in period in 2016 and climate change scenarios (Scenarios of RCP4.5, RCP8.5 for 2030 and 2050). The results show that flooding has increased in both flood area and depth in the future, especially in the climate change scenario RCP4.5 for 2050 with flood area simulated about 8757,02 ha (occupying 1,96\% of the city's total area) and RCP8.5 for 2050 with an area of 9039,91 ha (accounting for $4,38 \%$ of the city's total area).
\end{abstract}

Keywords: MIKE FLOOD; Flooding; Sea level rise; Extreme rain; Ho Chi Minh City. 